\title{
Fatores prognósticos e preditivos dos tumores caninos definidos com auxílio da imuno-histoquímica
}

\author{
Prognostic and predictive factors of caninetumours defined with immunohistochemistry’s assistance
}

\author{
Rodrigo dos Santos Horta ${ }^{{ }^{*}}$ Mariana de Pádua Costa ${ }^{\mathrm{I}}$ Gleidice Eunice Lavalle ${ }^{\mathrm{II}}$ \\ Roberto Baracat de AraújoI Geovanni Dantas CassaliIII
}

\section{- REVISÃO BIBLIOGRÁFICA -}

RESUMO

A imuno-histoquímica pode ser aplicada na oncologia veterinária para a definição do imunofenótipo neoplásico, com possibilidades ilimitadas de utilização. A técnica baseia-se na identificação de antígenos "in situ”, que podem apresentar valor prognóstico e terapêutico. A expressão de receptores de estrógeno e progesterona está diretamente relacionada ao melhor prognóstico para os neoplasmas mamários, enquanto a super-expressão do receptor KIT (CD117), proteínas Ki-67 (MIB-1), VEGF, CD31 e COX-2 podem ser associados à progressão tumoral para vários tipos histológicos. Essa associação possui valor preditivo em potencial, tendo em vista a possibilidade da utilização de bloqueadores específicos. Esta revisão tem como objetivo apresentar as possibilidades da utilização da imunohistoquímica nos tumores de cães, visando à definição mais precisa do prognóstico e a indicação de tratamentos específicos para cada paciente.

Palavras-chave: patologia, oncologia, cão, neoplasias, prognóstico.

\section{ABSTRACT}

Immunohistochemistry can be applied in veterinary oncology to define the immunophenotype of neoplastic cells with unlimited possibilities of application. The technique is based on the identification of antigens "in situ", which may have prognostic and therapeutic value. Expression of estrogen and progesterone is directly related to better prognosis for breast cancer, while over-expression of receptor KIT (CD117) proteins Ki-67 (MIB-1), COX-2, VEGF and CD31 can be associated with tumor progression for several histological types. This association has a potential predictive value, due to the possibility of using specific blockers. This revision aims at presenting the possibilities of immunohistochemical's application in tumors of dogs, searching for a more precise definition of the prognosis and indication of specific treatments for each patient.

Key words: pathology, oncology, dog, neoplasms, prognosis.

\section{INTRODUÇÃO}

O câncer é a principal causa de morte em cães de países desenvolvidos (CRAIG, 2001; PROSCHOWSKY et al., 2003). Estudos realizados no Brasil apontam as neoplasias como a segunda maior causa de mortes em animais de companhia (BENTUBO et al., 2007) e como a primeira, em animais idosos (FIGHERA et al., 2008). Esse fato decorre do aumento da expectativa de vida desses animais, relacionado a melhorias na prevenção de doenças infecciosas e parasitárias, nutrição, terapêutica e prática médica (WITHROW, 2007).

A definição de um prognóstico correto e o sucesso do tratamento estão diretamente relacionados com a anatomopatologia do tumor, sendo o exame histopatológico imprescindível na oncologia (WERNER

\footnotetext{
IDepartamento de Clínica e Cirurgia Veterinárias, Escola de Veterinária, Universidade Federal de Minas Gerais (UFMG), Av. Antônio Carlos, 6627, CP 567, 30161-970, Belo Horizonte, MG, Brasil. E-mail: rodrigohvet@gmail.com.*Autor para correspondência.

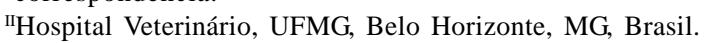

IIIDepartamento de Patologia Geral, Instituto de Ciências Biológicas, UFMG, Belo Horizonte, MG, Brasil.
} 
\& WERNER, 2009). No entanto, o grande número de informações acerca da biologia tumoral de diferentes tipos neoplásicos em cada espécie, exige um diagnóstico mais acurado, abrangendo características celulares e moleculares dos neoplasmas que vão além da definição de malignidade (RAMOS-VARA et al., 2008).

Com o advento da imunopatologia a partir de 1940, surgiram as primeiras técnicas imunohistoquímicas. Elas se baseiam na utilização de anticorpos para identificação de um antígeno "in situ”, em tecido fresco ou cortes histológicos processados rotineiramente (LEONG \& WRIGHT, 1987; RAMOSVARA, 2005; RAMOS-VARA, 2011). Para tanto, são aplicados anticorpos primários monoclonais ou policlonais capazes de reagirem com um único epítopo antigênico ou com vários epítopos de um mesmo antígeno, respectivamente (RAMOS-VARA, 2005; AMORIM, 2009). Em seguida, é adicionado um anticorpo secundário, direcionado contra a espécie animal em que foi produzido o anticorpo primário (HSU et al., 1981). A ligação entre o anticorpo e o antígeno não pode ser visualizada na microscopia de luz, a não ser que esta esteja marcada com componentes fluorescentes, enzimas ou metais (RAMOS-VARA, 2005). As enzimas são os componentes mais utilizados, com destaque para a peroxidase que, mediante a imunorreatividade e presença de um cromógeno, produz um precipitado marrom no sítio da ligação antígenoanticorpo (RAMOS-VARA, 2011).

Anticorpos comerciais utilizados contra epítopos antigênicos humanos ou outras espécies devem ser testados antes da aplicação na rotina da clínica de animais de companhia (RAMOS-VARA et al., 2008). É necessário que haja reação cruzada entre as proteínas de cada espécie para que o anticorpo se ligue ao antígeno (RAMOS-VARA, 2005; AMORIM, 2009). Alguns marcadores imuno-histoquímicos só podem ser aplicados em tecido fresco ou congelado (RAMOS-VARA, 2011). O processamento de rotina com fixação do material em formol impossibilita a utilização de alguns anticorpos (FERNANDEZ et al., 2005).

A imuno-histoquímica pode ser aplicada na oncologia veterinária, como ferramenta auxiliar, para o diagnóstico exato de neoplasmas indiferenciados e determinação da origem de metástases (WERNER et al., 2005; RAMOS-VARA et al., 2008). A identificação de receptores celulares e moléculas relacionadas à progressão tumoral permite caracterizar o imunofenótipo das células neoplásicas (MOHAMMED et al., 2011), constituindo fatores prognósticos e preditivos importantes (WERNER et al., 2005; RAMOSVARA et al., 2008).
Segundo ABREU \& KOIFMAN (2002), fatores prognósticos são parâmetros possíveis de serem mensurados no momento do primeiro diagnóstico e que podem ser utilizados para a classificação dos pacientes oncológicos em pelo menos três categorias. A primeira é caracterizada pelos pacientes cujo prognóstico é tão bom que dispensa a necessidade de tratamentos adjuvantes à cirurgia. A segunda é representada pelos indivíduos que apresentam maiores riscos de disseminação ou progressão tumoral, podendo ser beneficiados por um tratamento adjuvante convencional ou mais agressivo. O terceiro grupo inclui pacientes que podem receber uma terapia de alvo molecular específica, direcionada ao imunofenótipo neoplásico (CHUN \& THAMM, 2007). Nessa categoria, o fator prognóstico torna-se mais interessante e assume um caráter preditivo da terapêutica a ser instituída (ABREU \& KOIFMAN, 2002).

O objetivo desta revisão é apresentar as possibilidades da utilização da imuno-histoquímica na oncologia veterinária de pequenos animais, visando a uma definição mais precisa do prognóstico e indicação de tratamentos específicos para cada paciente, considerando o imunofenótipo neoplásico.

\section{DESENVOLVIMENTO}

Marcadores celulares nos tumores mamários

A expressão de determinadas moléculas nos neoplasmas mamários está diretamente relacionada à progressão da doença e permite categorizar os pacientes em diferentes grupos prognósticos (ROUZIER et al., 2005). A imuno-histoquímica é utilizada de forma rotineira para o câncer de mama da mulher (PEROU et al., 2000) e permite a definição de pelo menos quatro grupos mais importantes quanto ao diagnóstico e tratamento (Tabela 1).

O receptor do fator de crescimento epidérmico (epidermal growth factor receptor, EGFR), codificado pelo proto-oncogene $c$-erbB-1, pertence à mesma família do HER-2 (codificado pelo gene c-erbB2). É expresso em $57 \%$ dos tumores mamários triplonegativos (fenótipo basal) das mulheres, sendo associado à pior sobrevida (VIALE et al., 2009). No entanto, a indicação de uma terapia-alvo para neoplasmas mamários com esse imunofenótipo ainda não está bem definida (PEROU et al., 2000; VIALE et al., 2009). Outros genes e proteínas expressos pelas células epiteliais e basais/mioepiteliais da mama também são explorados com expressão muito variável e importância prognóstica/preditiva pouco esclarecida (RAKHA et al., 2008). A super-expressão dos fatores de crescimento epidermal EGFR e HER2 nos carcinomas 
Tabela 1 - Imunofenótipo do câncer de mama na mulher e sua relação com a graduação histológica e predição terapêutica.

\begin{tabular}{|c|c|c|c|c|c|}
\hline Grupo & $\mathrm{ER}^{*}$ & $\mathrm{PR}^{*}$ & Her-2* & Graduação & Terapia específica \\
\hline Luminal-A & + & + & - & Baixa & $\begin{array}{l}\text { Inibidores de ER* } \\
\quad \text { (tamoxifeno) }\end{array}$ \\
\hline Luminal-B & + & + & + & Intermediária & $\begin{array}{l}\text { Inibidores de ER* } \\
\quad \text { (tamoxifeno) }\end{array}$ \\
\hline HER2 & - & - & + & Alta & $\begin{array}{l}\text { Inibidores de HER-2* } \\
\text { (trastuzumab) }\end{array}$ \\
\hline Basal & - & - & - & Alta & Em estudo \\
\hline
\end{tabular}

*(ER - receptor de estrógeno, PR - receptor de progesterona, HER-2 - receptor de fator de crescimento epidérmico humano-2, + imunomarcação positiva, - imunomarcação negativa). Adaptado de PEROU et al., 2000.

mamários da cadela possivelmente estão relacionados ao desenvolvimento e progressão tumoral, mas os resultados são controversos (RUTTEMAN et al., 1994; DUTRA et al., 2004; HSU et al., 2009). Em um estudo realizado por BERTAGNOLLI et al. (2011), foi identificada maior expressão de EGFR nos componentes malignos dos tumores mamários mistos da cadela, sugerindo participação desse receptor na aquisição do fenótipo epitelial maligno. O mesmo resultado não foi observado para os receptores HER-2.

Assim como ocorre na espécie humana (PEROU et al., 2000), a expressão de receptores de estrógeno e progesterona é claramente relacionada ao melhor prognóstico dos pacientes caninos com carcinomas mamários (GRAHAM et al., 1999; SORENMO, 2003). A inibição dos receptores de estrógeno, por meio de drogas anti-estrogênicas, como o tamoxifeno e a ovário-histerectomia, podem influenciar na sobrevida desses pacientes (SORENMO, 2003; LANA et al., 2007; TAVARES et al., 2010). No entanto, apesar do potencial terapêutico, o tamoxifeno pode promover efeitos colaterais graves na cadela relacionados ao efeito agonista em outros tecidos, como, por exemplo, no útero, aumentando o risco do desenvolvimento de piometra (TAVARES et al., 2010). $\mathrm{Na}$ gata, existem indícios de que a perda da dependência hormonal ocorra em estágios precoces do desenvolvimento dos neoplasmas mamários, geralmente associados a um pior prognóstico (RUTTEMAN et al., 1991).

Tumores mistos são neoplasmas frequentes na mama da cadela e estão associados ao desenvolvimento de focos carcinomatosos em seu componente epitelial (BERTAGNOLLI et al., 2009). Essa transformação maligna dá origem aos carcinomas em tumores mistos "in situ”, ainda delimitados pelas células mioepiteliais, ou invasores, cuja progressão tumoral encontra-se mais avançada (GARTNER et al., 1999; BERTAGNOLLI et al., 2009). A marcação imunohistoquímica específica para a-actina (proteína expressa no citoplasma de células musculares lisas) e p63 (proteína codificada pelo gene p63 e expressa no núcleo das células mioepiteliais) pode auxiliar o patologista a avaliar a integridade da camada de células mioepiteliais. A perda da expressão dessas moléculas pode ser associada a um pior prognóstico (GAMA et al., 2003).

A E-caderina está relacionada à adesão celular e a variação de sua expressão pode representar um fator prognóstico para os adenocarcinomas mamários da mulher (KNUDSEN \& WHEELOCK, 2005) e da cadela (PIEKARZ, 2007). Imuno-marcações reduzidas de E-caderina estão associadas ao fenótipo maligno e a perda de sua expressão pode estar relacionada ao desprendimento celular, que favorece a disseminação tumoral (PIEKARZ, 2007). No entanto, observa-se a super-expressão dessa proteína em focos metastáticos e carcinomas inflamatórios, o que sugere uma dinâmica reversível na produção da E-caderina, de forma que sua re-expressão possa ser importante para o crescimento tumoral (BRUNETTI et al., 2005).

Marcadores celulares no linfoma

O prognóstico para o linfoma em cães e gatos também está diretamente relacionado ao imunofenótipo do neoplasma, dentre outras características (VAIL \& YOUNG, 2007). As células leucocitárias têm moléculas do citoplasma, núcleo e membrana celular conhecidas como grupos de diferenciação (cluster of differentiation, CD), o que permite distinguir linfócitos T, positivos para CD3, de linfócitos B, reativos para CD79a (AMORIM, 2009). Linfomas de células T apresentam pior prognóstico em comparação ao de células $B$, sendo associados a períodos mais curtos de remissão e menor sobrevida (VAIL \& YOUNG, 2007).

Marcadores celulares no mastocitoma canino O proto-oncogene $c$-KIT codifica o receptor tirosina-quinase KIT (CD117), cujo substrato é identificado como fator de crescimento de mastócito/ células-tronco (mast/stem cell growth factor, SCGF), ou simplesmente ligante KIT (THAMM \& VAIL, 2007). 
Mutações no $c$-KIT (resultando na ativação em oncogene) e expressão/localização aberrante do receptor KIT estão associadas à patogênese de diversas doenças neoplásicas no cão e na espécie humana (WEBSTER et al., 2006).

O ligante KIT e seu respectivo receptor atuam como um modulador do desenvolvimento e da função de mastócitos (THAMM \& VAIL, 2007). A expressão de CD117 nos mastocitomas caninos é elevada, sendo possível observar três padrões de imunomarcação com diferenças no prognóstico. KIT I é a marcação perimembranosa, ocorrendo em 73\% dos mastocitomas de grau I, 69\% dos mastocitomas de grau II e 31\% dos mastocitomas de grau III; KIT II é a marcação citoplasmática focal, observada em $28 \%$ dos mastocitomas de grau I, 24\% dos mastocitomas de grau II e 39\% dos mastocitomas de grau III; KIT III é a marcação citoplasmática difusa que ocorre em aproximadamente $30 \%$ dos mastocitomas de grau III (ARAÚJO, 2011). Os padrões II e III de imunomarcação representam uma localização aberrante da proteína e estão relacionados à maior risco de recidiva local e menor sobrevida, indicando pior comportamento biológico (WEBSTER et al., 2006). WEBSTER et al. (2006) observaram maior ocorrência de mutações no gene $c$-KIT em mastocitomas caninos de graduação mais elevada (graus II e III). No entanto, alguns pacientes com mutações identificadas no $c-K I T$ não apresentaram expressão aberrante do receptor KIT. Isso sugere que fatores adicionais possam ser responsáveis pela localização aberrante deste receptor nos mastocitomas caninos (WEBSTER et al., 2006). No homem, a expressão aberrante do receptor KIT já foi observada no câncer de pequenas células do pulmão e no câncer de próstata, enquanto mutações no $c$-KIT foram associadas ao desenvolvimento do tumor estromal gastrointestinal (WEBSTER et al., 2006).

A utilização de inibidores dos receptores tirosina-quinase representa uma terapia-alvo relevante no tratamento do mastocitoma canino (YAMADA et al., 2011). O toceranib é um potente inibidor da ligação do ATP no sítio das quinases, particularmente nos receptores do tipo KIT, bloqueando sua fosforilação (ABRAMS et al., 2003; LONDON et al., 2009). LONDON et al. (2009) selecionaram cães com mastocitomas recorrentes de graus II e III e demonstraram a eficácia do fosfato de toceranib em $60 \%$ dos pacientes com mutação no c-KIT e em $31,3 \%$ dos pacientes sem mutação. Os resultados significativos desse estudo podem justificar a importância da marcação imunohistoquímica para CD117 e identificação da mutação no gene $c-K I T$, a fim de predizer a resposta ao tratamento.
Marcadores de proliferação celular

A imuno-histoquímica pode ser utilizada também para a marcação do índice de proliferação celular em diferentes neoplasmas. Alguns anticorpos ligam-se apenas às células em replicação, o que permite a avaliação da taxa de proliferação tumoral que, por sua vez, pode ser associada ao prognóstico (VAIL \& WITHROW, 2007, CASSALI et al., 2011). De uma forma geral, tumores com maiores índices proliferativos apresentam curso mais agressivo com aumento do risco de metástases, mas melhor resposta à quimioterapia (SORENMO, 2003). O antígeno nuclear de proliferação celular (proliferating cell nuclear antigen, PCNA), expresso principalmente na fase $\mathrm{S}$ do ciclo celular e a proteína Ki-67 (reconhecida principalmente pelo anticorpo monoclonal MIB-1), expressa em todas as fases, exceto G0, representam os principais marcadores utilizados para definição da taxa de proliferação celular. O PCNA possui meia-vida muito longa, o que pode resultar em superestimação do número de células em divisão (AMORIM, 2009). Linfomas caninos de alto e baixo grau possuem taxa de multiplicação celular distintas. Esse fato justifica as diferenças observadas na resposta à quimioterapia e velocidade de progressão da doença (KIUPEL et al., 1999). Deve-se lembrar que esses marcadores reagem com as células em replicação, mas não detectam a velocidade de proliferação, que varia conforme a duração do ciclo biológico da célula envolvida (AMORIM, 2009).

\section{Marcadores de angiogênese tumoral}

As células tumorais produzem fatores próangiogênicos, como, por exemplo, o fator de crescimento do endotélio vascular (vascular endothelial growth factor, VEGF). A formação de novos vasos sanguíneos, ou angiogênese, é essencial para o crescimento, manutenção e disseminação de um neoplasma (ARGYLE \& KHANNA, 2007). A superexpressão de VEGF pode ser avaliada pela marcação imuno-histoquímica e representa um fator prognóstico ruim independente (AMORIM, 2009). A ação de fatores angiogênicos pode ser estimulada por hormônios e outras substâncias mediante a expressão de receptores dessas moléculas na célula tumoral (ARGYLE \& KHANNA, 2007).

De forma indireta, pode-se avaliar a angiogênese tumoral medindo-se a densidade de microvasos através de imunomarcação com CD31, glicoproteína de origem endotelial expressa apenas em vasos sanguíneos (LAVALLE et al., 2009; MOHAMMED et al., 2011). No entanto, nem sempre há correlação entre a densidade microvascular e a expressão de VEGF, visto que outros fatores pró- 
angiogênicos também são necessários para maturação e funcionamento dos novos vasos (AMORIM, 2009), com destaque para o fator de crescimento derivado de plaquetas (platelet-derived growth factor, PDGF), fator de crescimento fibroblástico ácido e básico (acidic fibroblast growth factor, aFGF e basic fibroblast growth factor, bFGF), prostaglandina $\mathrm{E}_{2}$ e interleucina8(CHUN \& THAMM, 2007).

A inibição de mecanismos pró-angiogênicos em pacientes com aumento da densidade de microvasos pode resultar em maior intervalo livre de doença e aumento da sobrevida dos pacientes, sendo, portanto, uma forma de tratamento direcionado bastante efetiva (SORENMO, 2003; CHUN \& THAMM, 2007).

\section{Ciclo-oxigenase-2 (COX-2)}

A ciclo-oxigenase é uma classe de enzimas catalíticas relacionada à formação de mediadores inflamatórios (BEAM et al., 2003). A isoforma COX-1 é expressa apenas constitutivamente e está relacionada à homeostase do indivíduo, enquanto a COX-2 pode ser expressa de forma induzível no sítio inflamatório (COSTA et al., 2002). Várias citocinas pró-inflamatórias, fatores de crescimento, carcinógenos e oncogenes podem induzir a atividade da COX-2. A expressão dessa enzima em processos neoplásicos, tanto na espécie humana, quanto em outras espécies animais está relacionada à progressão tumoral, sendo considerada um fator de prognóstico ruim para vários tipos histológicos (CHUN \& THAMM, 2007). A COX-2 e seus produtos inibem a apoptose (aumentando a expressão de proteínas anti-apoptóticas homólogas de células B, como o Bcl-2), diminuem a adesão celular, destroem a membrana basal, induzem a proliferação celular, favorecem a angiogênese (aumentando a produção de VEGF) e mantêm a resposta inflamatória, que, por sua vez, contribui para a carcinogênese (COSTA et al., 2002; CHUN \& THAMM, 2007; CASSALI et al., 2011).

A marcação imuno-histoquímica de COX-2 é maior em mastocitomas e nos neoplasmas mamários caninos de graduação mais elevada (AMORIM, 2009; CASSALI et al., 2011), além de representar um valor preditivo em potencial, tendo em vista a possibilidade da associação de inibidores seletivos da COX-2, como o firocoxib, em tratamentos adjuvantes (LAVALLE et al., 2009; CASSALI et al., 2011). No entanto, expressões reduzidas de ciclo-oxigenase-2 em diferentes neoplasmas felinos sugerem um baixo poder preditivo desse marcador nessa espécie (BEAM et al., 2003).

\section{CONCLUSÃO}

As possibilidades para utilização da técnica imuno-histoquímica em oncologia veterinária são ilimitadas. A avaliação da proliferação celular, angiogênese, expressão de COX-2 e outros marcadores celulares representam fatores prognósticos e preditivos para inúmeros processos neoplásicos.

Infelizmente, na Medicina Veterinária, a análise imuno-histoquímica ainda não é rotina e até mesmo o exame anatomopatológico tem sido, por vezes, negligenciado. A definição de um prognóstico preciso e a escolha de um tratamento mais adequado só podem ser inferidos a partir da obtenção de um diagnóstico detalhado, sendo necessário, em alguns casos, explorar o imunofenótipo neoplásico (CASSALI et al., 2011).

\section{AGRADECIMENTO}

Fundação de Estudo e Pesquisa em Medicina Veterinária e Zootecnia (FEPMVZ) - Escola de Veterinária da UFMG.

\section{REFERÊNCIAS}

ABRAMS, T.J. et al. Preclinical evaluation of the tyrosine kinase inhibitor SU11248 as a single agent and in combination with "standard of care" therapeutic agents for the treatment of breast cancer. Molecular Cancer Therapy, v.2, p.471-478, 2003. Disponível em: <http://mct.aacrjournals.org/content/2/ 10/1011.full.pdf+html>. Acesso em: 06 fev. 2012.

ABREU, A.; KOIFMAN, S. Fatores prognósticos no câncer da mama feminina. Revista Brasileira de Cancerologia, v.48, n.1, p.113-131, 2002. Disponível em: <http://www.inca.gov.br/ rbc/n_48/v01/pdf/revisao.pdf>. Acesso em: 06 fev. 2012.

AMORIM, R.L. Imunoistoquímica em oncologia veterinária. In: DALECK, C.R. et al. Oncologia em cães e gatos. São Paulo: Roca, 2009. Cap.8, p.135-150.

ARAÚJO, M.R. Estudo retrospectivo e prospectivo dos tumores cutâneos em cães e diferenciação dos tumores cutâneos de células redondas pela imuno-histoquímica. 2011. 102f. Dissertação (Mestrado em Ciência Animal) Curso de Pós-graduação em Ciência Animal, Universidade Federal de Minas Gerais, MG.

ARGYLE, D.J., KHANNA, C. Tumor biology and metastasis. In: WITHROW, S.J.; MACEWEN, E.G. Withrow and MacEwen's small animal clinical oncology. 4.ed. Philadelphia: Saunders, 2007. Cap.2, p.31-53.

BEAM, S.L. et al. An immunohistochemical study of cyclooxygenase-2 expression in various feline neoplasms. Veterinary Pathology, v.40, p.496-500, 2003. Disponível em: <http://vet.sagepub.com/content/40/5/496.long>. Acesso em: 06 fev. 2012. doi: 10.1354/vp.40-5-496.

BENTUBO, H.D.L. et al. Expectativa de vida e causas de morte em cães na área metropolitana de São Paulo (Brasil). 
Ciência Rural, v.37, n.4, p.1021-1036, 2007. Disponível em: <http://dx.doi.org/10.1590/S0103-84782007000400016>. Acesso em: 06 fev. 2012. doi: 10.1590/S010384782007000400016 .

BERTAGNOLLI, A.C. et al. Immunohistochemical expression of p63 and ?Np63 in mixed tumors of canine mammary glands and its relation with p53 expression. Veterinary Pathology, v.46, p.407-415, 2009. Disponível em: <http:// vet.sagepub.com/content/46/3/407.long>. Acesso em: $06 \mathrm{fev}$. 2012. doi: 10.1354/vp.08-VP-0128-C-FL.

BERTAGNOLLI, A.C. et al. Canine mammary mixed tumours: imunohistochemical expressions of EGFR and HER-2. Australian Veterinary Journal, v.89, p.312-317, 2011. Disponível em: < http://onlinelibrary.wiley.com/doi/10.1111/ j.1751-0813.2011.00803.x/pdf>. Acesso em: 06 fev. 2012. doi: 10.1111/j.1751-0813.2011.00803.x.

BRUNETTI, B. et al. E-cadherin and ß-catenin reduction influence invasion but not proliferation and survival in canine malignant mammary tumor. Veterinary Pathology, v.42, p.781-787, 2005. Disponível em: <http://vet.sagepub.com/ content/42/6/781.long>. Acesso em: 06 fev. 2012. doi: 10.1354/vp.42-6-781.

CASSALI, G.D. et al. Consensus for the diagnosis, prognosis and treatment of canine mammary tumors. Brazilian Journal of Veterinary Pathology, v.4, n.2, p.153-180, 2011. Disponível em: <http://www.abpv.vet.br/upload/documentos/ D O W N L O A D - F U L L - A R T I C L E - 29 20881_2011_7_11_14_42.pdf>. Acesso em: 06 fev. 2012.

CHUN, R., THAMM, D.H. Targeting angiogenesis and tumor vasculature. In: WITHROW, S.J.; MACEWEN, E.G. Withrow and MacEwen's small animal clinical oncology. 4.ed. Philadelfia: Saunders, 2007. Cap.14, section E, p.259-266.

COSTA, C. et al. Cyclo-oxygenase-2 expression is associated with angiogenesis and lymph node metastasis in human breast cancer. Journal of Clinical Pathology, v.55, p.429-434, 2002. Disponível em: <http://jcp.bmj.com/content/55/6/ 429.full>. Acesso em: 06 fev. 2012.

CRAIG, L.E. Cause of death in dogs according to breed: a necropsy survey of five breeds. Journal of the American Animal Hospital Association, v.37, p.438-443, 2001. Disponível em: <http://www.jaaha.org/content/37/5/438.long>. Acesso em: 06 fev. 2012.

DUTRA, A.P. et al. c-erbB-2 expression and nuclear pleomorphism in canine mammary tumors. Brazilian Journal of Medical and Biological Research. v.37, p.16731681, 2004. Disponível em: < http://www.scielo.br/pdf/bjmbr/ v37n11/5115.pdf $>$. Acesso em: 06 fev. 2012. doi: 10.1590/ S0100-879X2004001100013.

FERNANDEZ, N.J. et al. Immunohistochemical and histochemical stains for differentiating canine cutaneous round cell tumours. Veterinary Pathology, v.42, p.437-445, 2005. Disponível em: <http://vet.sagepub.com/content/42/4/437.long>. Acesso em: 06 fev. 2012. doi: 10.1354/vp.42-4-437.

FIGHERA, R.A. et. al. Causas de morte e razões para eutanásia de cães da Mesorregião do Centro Ocidental Rio-Grandense (19652004). Pesquisa Veterinária Brasileira, v.28, n.4, p.223-230, 2008. Disponivel em: $<$ http://www.scielo.br/scielo.php?pid=S0100736X2008000400005\&script=sci_arttext $>$. Acesso em: $06 \mathrm{fev}$. 2012. doi: 10.1590/S0100-736X2008000400005.
GAMA, A. et al. P63: a novel myoepithelial cell marker in canine mammary tissues. Veterinary Pathology, v.40, p.412440, 2003. Disponível em: <http://vet.sagepub.com/content/ 40/4/412.long>. Acesso em: 06 fev. 2012. doi: 10.1354/vp.404-412.

GÄRTNER, F. et al. DNA measurement and immunohistochemical characterization of epithelial and mesenchymal cells in canine mixed mammary tumors: putative evidence for common histogenesis. Veterinary Journal, v.158, p.39-47, 1999. Disponível em: <http:// www.sciencedirect.com/science/article/pi i / S1090023398903331>. Acesso em: 06 fev. 2012. doi: 10.1053/ tvjl.1998.0333.

GRAHAM, J.C. et al. Immunohistochemical assay for detecting estrogen receptors in canine mammary tumors. American Journal of Veterinary Research, v.60, p.627-630, 1999.

HSU, S.M. et al. Use of avidin-biotin-peroxidase complex (ABC) in immunoperoxidase techniques: a comparison between ABC and unlabeled antibody (PAP) procedures. Journal of Histochemical and Cytochemistry, v.29, p.577-580, 1981. Disponível em: <http://jhc.sagepub.com/content/29/4/577>. Acesso em: 06 fev. 2012. doi: 10.1177/29.4.6166661.

HSU, W.L. et al. Increased survival in dogs with malignant mammary tumours overexpressing HER-2 protein and detection of a silent single nucleotide polymorphism in the canine HER2 gene. Veterinary Journal, v.180, p.116-123, 2009. Disponível em: <http://www.sciencedirect.com/science/article/ pii/S1090023307003589>. Acesso: em 06 fev. 2012. doi: 10.1016/j.tvjl.2007.10.013.

KIUPEL, M. et al. Prognostic factors for treated canine malignant lymphoma. Veterinary Pathology, v.35, p.292300, 1999. Disponível em: <http://vet.sagepub.com/content/ 36/4/292.long>. Acesso em: 06 fev. 2012. doi: 10.1354/vp.364-292.

KNUDSEN, K.A.; WHEELOCK, M.J. Cadherins and the mammary gland. Journal of Cellular Biochemistry, v.95, p.488-496, 2005. Disponível em: <http://onlinelibrary.wiley.com/ doi/10.1002/jcb.20419/abstract>. Acesso em: 06 fev. 2012. doi: $10.1002 /$ jcb.20419.

LANA, S.E. et al. Tumors of the mammary gland. In: WITHROW, S.J.; MACEWEN, E.G. Withrow and MacEwen's small animal clinical oncology. 4.ed. Philadelphia: Saunders, 2007. Cap.26, p.619-636.

LAVALLE, G.E. et al. Cox-2 expression in canine mammary carcinomas: correlation with angiogenesis (or microvessel density) and overall survival. Veterinary Pathology, v.46, p.1-6, 2009. Disponível em: <http://vet.sagepub.com/content/ 46/6/1275.full.pdf >. Acesso em: 06 fev. 2012. doi: 10.1354/ vp.08-VP-0226-C-FL.

LEONG, A.S-Y.; WRIGHT, J. The contribution of immunohistochemical staining in tumor diagnosis. Histopathology, v.11, n.12, p.1295-1305, 1987. Disponível em: <http://onlinelibrary.wiley.com/doi/10.1111/j.13652559.1987.tb01874.x/pdf>. Acesso em: 06 fev. 2012. doi: 10.1111/j.1365-2559.1987.tb01874.x.

LONDON, C.A. et al. Multi-center, placebo-controlled, doubleblind, randomized study of oral toceranib phosphate (SU11654), a receptor tyrosine kinase inhibitor, for the treatment of dogs with 
recurrent (either local or distant) mast cell tumor following surgical excision. Clinical Cancer Research, v.15, p.3856-3865, 2009. Disponível em: <http://clincancerres.aacrjournals.org/content/15/ 11/3856.full.pdf+html>. Acesso em: 06 fev. 2012. doi: 10.1158/ 1078-0432.CCR-08-1860.

MOHAMMED, R.A.A. et al. Objective assessment of lymphatic and blood vascular invasion in lymph node-negative breast carcinoma: findings from a large case series with longterm follow-up. Journal of Pathology, v.223, p.358-365 2011. Disponível em: <http://onlinelibrary.wiley.com/doi/ 10.1002/path.2810/full >. Acesso em: 06 fev. 2012. doi: 10.1002 /path. 2810 .

PEROU, C.M. et al. Molecular portraits of human breast tumours. Nature, v.406, p.747-752, 2000. Disponível em: <http://www.nature.com/nature/journal/v406/n6797/full/ 406747a0.html>. Acesso em: 06 fev. 2012. doi: 10.1038/ 35021093.

PIEKARZ, C.H. Expressão da E-caderina no prognóstico de neoplasias mamárias de cadelas. 2007. 90f. Dissertação (Mestrado em Ciências Veterinárias) - Programa de Pósgraduação em Ciências Veterinárias, Universidade Federal do Paraná, PR.

PROSCHOWSKY, H.F et al. Mortality of purebred and mixedbreed dogs in Denmark. Preventive Veterinary Medicine, v.58, p.63-74, 2003. Disponível em: <http://www.sciencedirect.com/ science/article/pii/S0167587703000102>. Acesso em: 06 fev. 2012. doi: 10.1016/S0167-5877(03)00010-2

RAKHA, E. et al. Are triple-negative and basal-like breast cancer synonymous? Clinical Cancer Research, v.14, n.2, p.618, 2008. Disponível em: <http://clincancerres.aacrjournals.org/ content/14/2/618.1.full>. Acesso em: 06 fev. 2012. doi: 10.1158/ 1078-0432.CCR-07-1943.

RAMOS-VARA, J.A. Technical aspects of immunohistochemistry. Veterinary Pathology, v.42, p.405-426, 2005. Disponível em: $<$ http://vet.sagepub.com/content/42/4/405.long>. Acesso em: 06 fev. 2012. doi: 10.1354/vp.42-4-405.

RAMOS-VARA, J.A. et al. Suggested guidelines for immunohistochemical techniques in veterinary diagnostic laboratories. Journal of Veterinary Diagnostic Investigation, v.20, p.393-413, 2008. Disponível em: <http:/ /vdi.sagepub.com/content/20/4/393.full>. Acesso em: $06 \mathrm{fev}$. 2012. doi: $10.1177 / 104063870802000401$

RAMOS-VARA, J.A. Principles and methods of immunohistochemistry. Methods in Molecular Biology, v.691, p.83-96, 2011. Disponível em: <http:// www.springerlink.com/content/j177270770651 kx 8/ \#section=800124\&page=1>. Acesso em: 06 fev. 2012. doi: 10.1007/978-1-60761-849-2_5.

ROUZIER, R. et al. Breast cancer molecular subtypes respond differently to preoperative chemotherapy. Clinical Cancer Research, v.11, n.16, p.5678-5685, 2005. Disponível em: $<$ http://clincancerres.aacrjournals.org/content/11/16 5678.full>. Acesso em: 06 fev. 2012. doi: 10.1158/10780432.CCR-04-2421.

RUTTEMAN, G.R. et al. Steroid receptors in mammary tumors of the cat. Acta Endocrinologica (Copenhagen), v.125, suppl.1, p.32-37, 1991.

RUTTEMAN, G.R. et al. Expression of epidermal growth factor receptor (EGFR) in non-affected and tumorous mammary tissue of female dogs. Breast Cancer Research and Treatment, v.30, p.139-146, 1994. Disponível em: <http:// www.springerlink.com/content/p7g4463xh0653232/>. Acesso em: 06 fev. 2012. doi: 10.1007/BF00666057.

SORENMO, K. Canine mammary gland tumors. Veterinary Clinics of North America: Small Animal Practice, v.33, p.573596, 2003. Disponível em: <http://www.vetsmall.theclinics.com/ article/S0195-5616\%2803\%2900020-2/fulltext>. Acesso em: 06 fev. 2012. doi: 10.1016/S0195-5616(03)00020-2.

TAVARES, W.L.F. et al. Evaluation of adverse effects in tamoxifen exposed healthy female dogs. Acta Veterinaria Scandinavica, v.52, n.67, p.6, 2010. Disponível em: <http:/ /www.actavetscand.com/content/52/1/67>. Acesso em: $06 \mathrm{fev}$. 2012. doi: 10.1186/1751-0147-52-67.

THAMM, D.H.; VAIL, D.M. Mast cell tumors. In: WITHROW, S.J.; MACEWEN, E.G. Withrow and MacEwen's small animal clinical oncology. 4.ed. Philadelphia: Saunders, 2007. Cap.19, p.402-424.

VAIL, D.M.; YOUNG, K.M. Canine lymphoma and lymphoid leukemia. In: WITHROW, S.J.; MACEWEN, E.G. Withrow and MacEwen's small animal clinical oncology. 4.ed. Philadelphia: Saunders, 2007. Cap.31, section A, p.699-733.

VAIL, D.M.; WITHROW, S.J. Tumors of the skin and subcutaneous tissues. In: WITHROW, S.J.; MACEWEN, E.G. Withrow and MacEwen's small animal clinical oncology. 4.ed. Philadelphia: Saunders, 2007. Cap.18, p.375-401.

VIALE, G. et al. Invasive ductal carcinoma of the breast with the "triple-negative" phenotype: prognostic implications of EGFR immunoreactivity. Breast Cancer Research and Treatment, v.116, n.2, p.317-328, 2009. Disponível em: <http://www.springerlink.com/content/871u5q13623g2220/>. Acesso em: 06 fev. 2012. doi: 10.1007/s10549-008-0206-z.

YAMADA, O. et al. Imatinib elicited a favorable response in a dog with a mast cell tumor carrying a c-kit c.1523A $>$ T mutation via suppression of constitutive KIT activation. Veterinary Immunology and Immunopathology, v.142, p.101-106, 2011. Disponível em: <http://www.sciencedirect.com/science/ article/pii/S016524271100119X >. Acesso em: 06 fev. 2012. doi: 10.1016/j.vetimm.2011.04.002.

WEBSTER, J.D. et al. The role of c-kit in tumorigenesis: evaluation in canine cutaneous mast cell tumours. Neoplasia, v.8, p.104-111, 2006. Disponível em: <http:// www.ncbi.nlm.nih.gov/pmc/articles/PMC1578516/>. Acesso em: 06 fev. 2012. doi: 10.1593/neo.05622.

WERNER, B. et al. Uso prático da imuno-histoquímica em patologia cirúrgica. Jornal Brasileiro de Patologia e Medicina Laboratorial, v.4, n.5, p.353-364, 2005. Disponível em: <http://dx.doi.org/10.1590/S167624442005000500011>. Acesso em: 06 fev. 2012. doi: 10.1590/ S1676-24442005000500011

WERNER, P.R.; WERNER, J. Avaliação histopatológica. In: DALECK, C.R. et al. Oncologia em cães e gatos. São Paulo: Roca, 2009. Cap.7, p.121-134.

WITHROW, S.J. Why worry about cancer in pets? Introduction. In: WITHROW, S.J.; MACEWEN, E.G. Withrow and MacEwen's small animal clinical oncology. 4.ed. Philadelphia: Saunders, 2007. p.15-17 